\title{
Tropical Cyclone Initialization and Prediction Based on Four-Dimensional Variational Data Assimilation
}

\author{
Chun-Chieh Wu and Kun-Hsuan ChOu \\ Department of Atmospheric Sciences, National Taiwan University, Taipei, Taiwan \\ YUQING WANG \\ International Pacific Research Center, School of Ocean and Earth Science and Technology, University of Hawaii at Manoa, \\ Honolulu, Hawaii \\ YING-Hwa KUO \\ National Center for Atmospheric Research, Boulder, Colorado
}

(Manuscript received 16 December 2003, in final form 4 January 2006)

\begin{abstract}
Issues on the initialization and simulation of tropical cyclones (TCs) have been studied here based on four-dimensional variational data assimilation. In particular, experiments have been carried out to assess 1) what the most critical parameters for the so-called bogus data assimilation are and 2) how the current procedures for the bogus data assimilation can be further improved.

It is shown that the assimilation of wind fields is more successful than that of pressure fields in improving the initial structure and prediction of TCs. It is emphasized that the geostrophic adjustment favors the pressure field to adjust to the wind field because the TC vortex is much smaller than the radius of Rossby deformation. The results suggest that a better initial condition in the wind field is critical to the simulation of TCs.

Experiments from this study also show that inclusion of the initial TC movement in the data assimilation window can help improve the track prediction, particularly during the early integration period. This method is able to shed light on the improvement of TC simulation based on the bogus data assimilation.

In all, the results add a theoretical interpretation of the importance of the wind field to the sea level pressure field in terms of geostrophic adjustment, as well as a time dimension of the bogus data assimilation, by assimilating a movable vortex in the four-dimensional variational data assimilation.
\end{abstract}

\section{Introduction}

Considerable progress has been made over the past decade or so in the prediction of tropical cyclone (TC) tracks with numerical models (e.g., Kurihara et al. 1993, 1995, 1998). Recent works (e.g., Liu et al. 1997, 1999; Zhang et al. 2000, 2001, 2002; Braun 2002) have also demonstrated the capability of high-resolution nonhydrostatic mesoscale models to realistically simulate the detailed mesoscale structure of a TC. Wang (2001, $2002 \mathrm{a}, \mathrm{b}, \mathrm{c})$ has demonstrated that a high-resolution

Corresponding author address: Dr. Chun-Chieh Wu, Dept. of Atmospheric Sciences, National Taiwan University, No. 1, Sec. 4, Roosevelt Rd., Taipei 106, Taiwan.

E-mail: cwu@typhoon.as.ntu.edu.tw model has the capability to simulate many aspects of TCs, including the inner core structure, the inner and outer spiral rainbands, and the vortex Rossby waves within the rapidly rotating eyewall.

Nevertheless, as a TC spends most of its lifetime over the tropical ocean, where conventional observations have always been sparsely made, the uncertainty and poor quality in initial conditions can lead to monumental errors in the numerical simulation and prediction of TCs. For example, Kurihara et al. (1995) have demonstrated that a better prediction could be achieved with the use of improved initialization procedures that better represent the initial environmental, as well as the vortex scale, flow, and mass fields. Moreover, Wu et al. (2000a) showed that numerical simulations of typhoon track and intensity tended to have some systematic bi- 
ases, which also varied with different initial conditions. Wang (1998) demonstrated that the vertical structure of the bogus vortex could affect the subsequent TC track and intensity predictions. These studies clearly point out that the improved initial condition is a crucial step toward improving the simulation and prediction of TCs.

Some new observations around TCs, such as Omega dropwindsondes from the synoptic flow experiments (Burpee et al. 1996; Tuleya and Lord 1997), Global Positioning System (GPS) dropsondes from the Gulfstream IV surveillance (Aberson 2002, 2003), and satellite-derived wind, temperature, and rainfall data (Negri and Adler 1993; Smith and Lee 1995; Velden et al. 1997; Liu 2002; Kummerow et al. 2000; Soden et al. 2001; Zou et al. 2001; Pu et al. 2002; Zhu et al. 2002), provide unprecedented data to improve the analysis of TCs. To make use of these available data or other new data, it is important to evaluate the potential impact these data can have, and to test the sensitivity of the simulation and prediction of TCs to different parameters and within different regions. Understanding these can be of great use for designing a cost-effective strategy for targeted observations of TCs (Morss et al. 2001; Majumdar et al. 2002a,b; Aberson 2003; Wu et al. 2005).

As the conventional observations usually have far less degrees of freedom than the model does, the fourdimensional variational data assimilation (4DVAR) has become one of the most advanced approaches to combining the observations with the model in such a way that the initial conditions are consistent with the model dynamics and physics (Guo et al. 2000). Based on 4DVAR, a bogus data assimilation (BDA) method has been developed by Zou and Xiao (2000) to improve the initial conditions for TC simulation. Given a specified sea level pressure (SLP) distribution, the BDA process can lead to a better initial typhoon structure. Zou and Xiao (2000) showed that with the better initialization procedure, the simulation of the track and intensity of Hurricane Felix (1995) was improved.

Xiao et al. (2000) expanded the work of Zou and Xiao (2000) by assimilating wind data into the model. Using the observed data, such as the minimum SLP, and/or the maximum wind speed and the radius of maximum wind, and based on an assumed idealized distribution of the SLP and/or three-dimensional (3D) wind structure, a dynamically consistent initial TC vortex was produced through the BDA. By comparing the simulation with different data used in BDA, they showed that the assimilation of only the SLP field was more effective than that of only the 3D wind field. Although based on a similar approach, $\mathrm{Pu}$ and Braun (2001) showed that the assimilation of wind fields would be more useful than that of the SLP field for improving the initial structure and prediction of TCs, while assimilating both the 3D wind and SLP fields provided the best results in simulating both the track and intensity of the storm. Pu and Braun (2001) suggested that the size of the bogus vortex might be responsible for the difference between their results and those of Zou and Xiao (2000).

The above studies present a useful direction for TC initialization using BDA. Nevertheless, important questions remain to be answered: 1) What are the most critical parameters for BDA? 2) And how can the current BDA procedures be further improved? The primary aims of this study are to clarify and investigate the related questions mentioned above. Following Kuo et al. (1997), we performed a set of quasi Observing Systems Simulation Experiments (OSSEs) to address the above questions about BDA.

\section{Control experiment}

\section{a. Experiment design}

We first construct the original reference data by running the fifth-generation Pennsylvania State University-National Center for Atmospheric Research Mesoscale Model (MM5) with relatively simple physics [Grell cumulus parameterization (Grell 1993), the Blackadar planetary boundary layer scheme (Blackadar 1979), the atmospheric radiation scheme of Dudhia (1993), and the simple ice cloud microphysics (Dudhia 1989)] in two nests (two-way interactive) at 90- and 30-km resolutions for Typhoon Zane (Wu et al. 2000b) for $72 \mathrm{~h}$ from 1200 UTC 27 September to 1200 UTC 30 September 1996. To allow time for the model to generate a realistic typhoon structure, we start the OSSEs at the 12-h forecast of the original reference data. Then we run the MM5 forward in the single inner mesh for 60 $\mathrm{h}$ from 0000 UTC 28 September to 1200 UTC 30 September, with the lateral boundary conditions updated from the original reference data. The result of this $60-\mathrm{h}$ simulation is regarded as the control experiment (see Fig. 1a with an initial minimum SLP of $968 \mathrm{hPa}$ ). The track from the control experiment (Fig. 2a) moved too much to the northeast, instead of the observed northnorthwestward movement at the first $12 \mathrm{~h}$. The difference between the track of the control experiment and the best track of Joint Typhoon Warning Center (JTWC) is about $218 \mathrm{~km}$ at $12 \mathrm{~h}$, and then decreases to 65 (181) km at $24(36) \mathrm{h}$. Note that the eastward turn at $36 \mathrm{~h}$ is well captured in the control experiment (see Fig. 2a). Meanwhile, the intensity in the control experiment is underestimated compared to the best-track minimum SLP of $955 \mathrm{hPa}$ by about $13 \mathrm{hPa}$ through the integration 

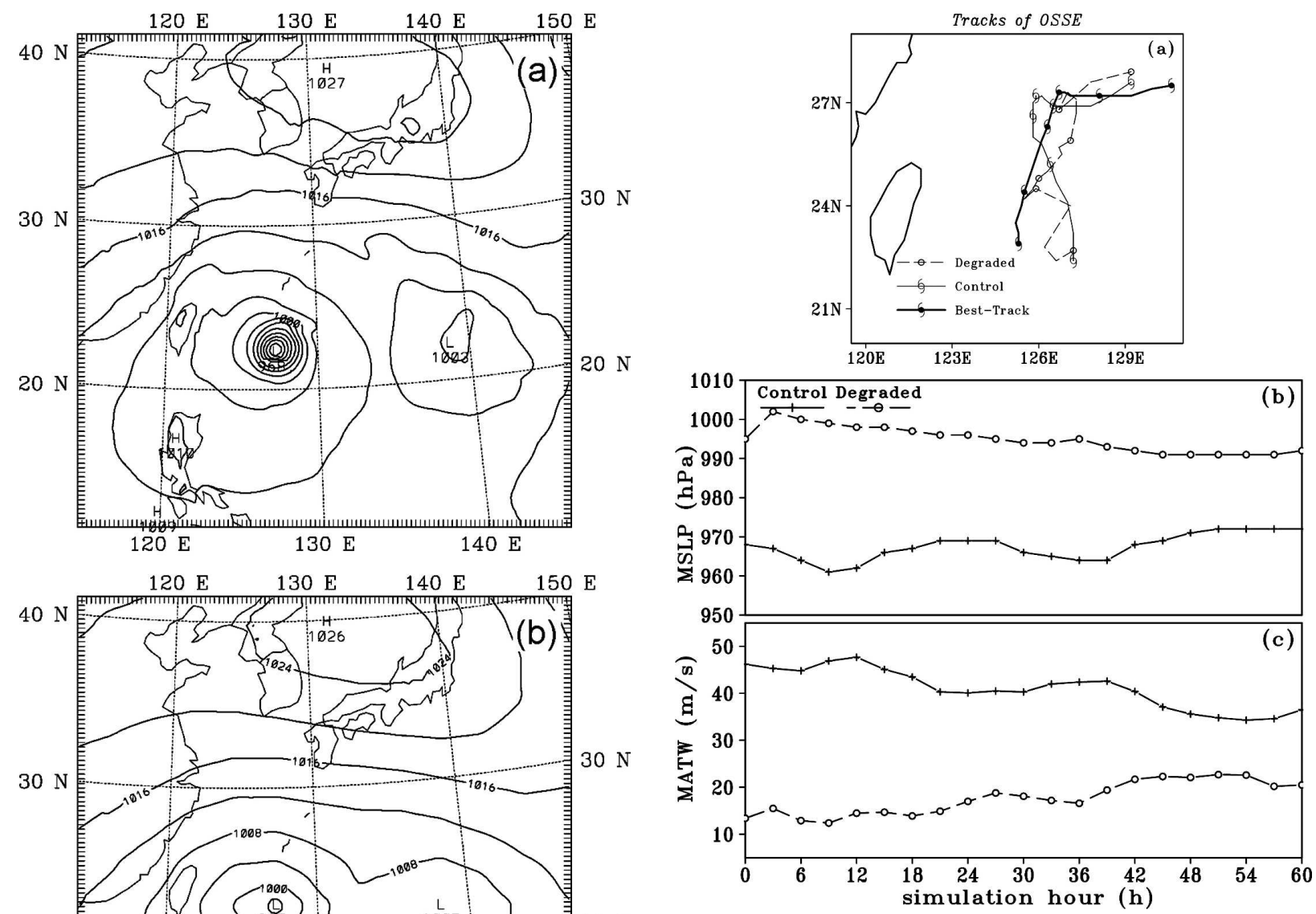

$20 \mathrm{~N}$

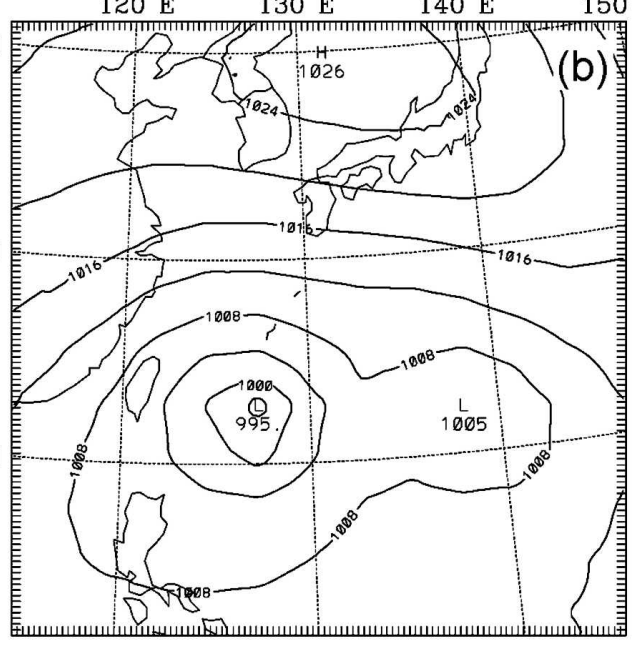

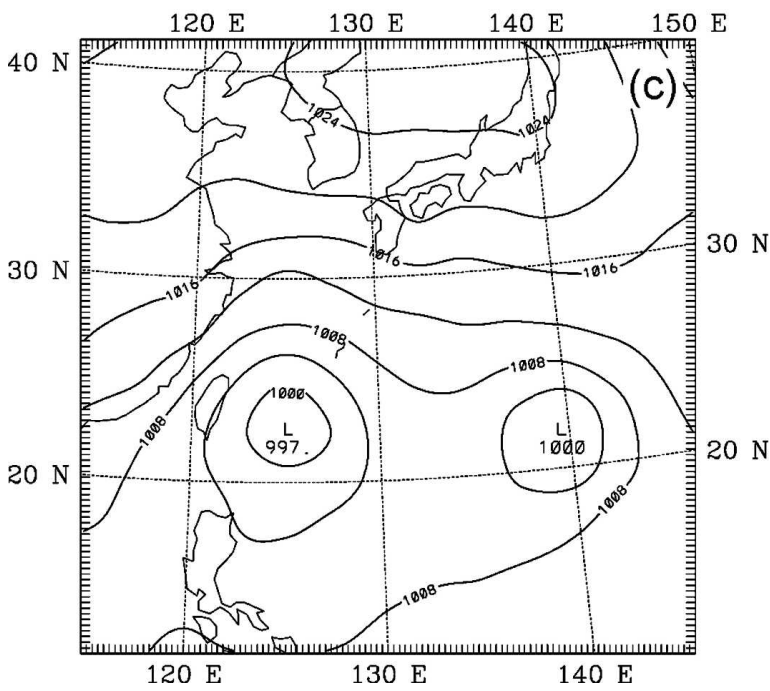

FIG. 1. Sea level pressure (contour interval of $4 \mathrm{hPa}$ ) at 0000 UTC 28 Sep 1996: (a) control experiment, (b) degraded experiment, and (c) ECMWF TOGA analysis.
FIG. 2. (a) The best track (JTWC) and the simulated tracks in both the control and degraded experiments for every $12 \mathrm{~h}$. Time evolutions of (b) the minimum central sea level pressure (MSLP; $\mathrm{hPa}$ ) and (c) the maximum azimuthally averaged tangential wind $\left(\mathrm{m} \mathrm{s}^{-1}\right)$ at the model level of $\sigma=0.87$.

period, likely due to the limitation of the model resolution. For a systematic evaluation of the OSSEs, we presume the control experiment as the model's true atmosphere (i.e., "nature run") for further comparison.

To assess the impact of different variables in BDA, we first degraded the quality of the original inner-nest reference data by successively applying a 1-2-1 smoothing operator (Kurihara et al. 1993) to create the degraded initial condition at 0000 UTC 28 September (see Fig. 1b, which has an initial minimum SLP of 995 $\mathrm{hPa}$ ), which has a quality roughly equivalent to that of a global analysis at $2.5^{\circ} \times 2.5^{\circ}$ resolution and resolves a weak initial tropical cyclone vortex [see Fig. 1c for the global analysis from the European Centre for MediumRange Forecasts (ECMWF) and Tropical Ocean Global Atmosphere (TOGA) at the same time]. Starting from the degraded initial condition, a 60-h simulation from 0000 UTC 28 September (the initial time for OSSEs) with the same model setup as the nature run is carried out to produce a set of data that can be re- 
TABLE 1. Summary of experiments.

\begin{tabular}{|c|c|c|c|c|}
\hline Experiment & $\begin{array}{c}\text { Variables for } \\
\text { data assimilation }\end{array}$ & $\begin{array}{l}\text { Data source in the core region } \\
\text { (inner } 600-\mathrm{km} \text { radius) }\end{array}$ & $\begin{array}{l}\text { Assimilated } \\
\text { data }\end{array}$ & $\begin{array}{l}\text { Assimilation } \\
\text { time window }\end{array}$ \\
\hline Control & \multicolumn{4}{|c|}{ The control experiment } \\
\hline Degraded & \multicolumn{4}{|c|}{ The degraded experiment } \\
\hline A1 & $p_{s}^{\prime}$ & Data from the control experiment at $0 \mathrm{~h}$ & Fixed* & $30 \mathrm{~min}$ \\
\hline A2 & $u, v$ & Same as above & Fixed & $30 \mathrm{~min}$ \\
\hline A3 & $u, v, p_{s}^{\prime}$ & Same as above & Fixed & $30 \mathrm{~min}$ \\
\hline B1 & $u, v, p_{s}^{\prime}$ & Data from the control experiment at $12 \mathrm{~h}$ & Fixed & $30 \mathrm{~min}$ \\
\hline B2 & $u, v, p_{s}^{\prime}$ & Same as above & Movable** & $3 \mathrm{~h}$ \\
\hline B3 & $u, v, p_{s}^{\prime}$ & Same as above & Movable & $6 \mathrm{~h}$ \\
\hline NO-DA & \multicolumn{4}{|c|}{ Simulation with the bogused vortex after Wu et al. (2002) without the 4DVAR data assimilation } \\
\hline DA-FIX & $u, v, p_{s}^{\prime}$ & Data from the bogused vortex of NO-DA & Fixed & $30 \mathrm{~min}$ \\
\hline DA-MOVE & $u, v, p_{s}^{\prime}$ & Same as above & Movable & $3 \mathrm{~h}$ \\
\hline $\mathrm{O} 1$ & \multicolumn{4}{|c|}{ As $A 3$, except that the value of $\mathbf{O}^{-1}$ is of the same value as $\mathbf{B}^{-1}$} \\
\hline O5 & \multicolumn{4}{|c|}{ As $A 3$, except that the value of $\mathbf{O}^{-1}$ is 5 times the value of $\mathbf{B}^{-1}$} \\
\hline $\mathrm{O} 10$ & \multicolumn{4}{|c|}{ As $A 3$, except that the value of $\mathbf{O}^{-1}$ is 10 times the value of $\mathbf{B}^{-1}$} \\
\hline W & \multicolumn{4}{|c|}{ As B1, except that the reference data are generated from the WRF model } \\
\hline
\end{tabular}

* Fixed: vortex location fixed at the initial location during the data assimilation period.

** Movable: vortex location moved following the track of the control experiment during the data assimilation period.

garded as the lower bound of the simulation, and serves as our degraded experiment (the second row in Table 1).

Consistent with the above 60-h simulation, the innernest domain is selected for data assimilation experiments using the MM5 Adjoint Modeling System (MM54DVAR) as described in Zou et al. (1997). Note that the model physics used in the adjoint system is slightly different from that used in the forward integration model, including the use of simple bulk aerodynamic planetary boundary layer scheme, stable precipitation, Grell cumulus parameterization, and no radiation.

\section{b. Results}

Figures 3a,b show zonal cross sections, through the storm center of the potential vorticity [PV; $1 \mathrm{PV}$ unit $\left.(\mathrm{PVU})=1 \times 10^{-6} \mathrm{~m}^{2} \mathrm{~s}^{-1} \mathrm{~K} \mathrm{~kg}^{-1}\right]$, wind speed, and potential temperature of the initial vortex for the control and degraded experiments. A much weaker initial vortex is represented in the degraded experiment (Fig. $3 b$ ) as compared to that in the control experiment (Fig. $3 a$ ), where high PV and warm potential temperature are present in the storm core surrounded by an eyewall (about $110 \mathrm{~km}$ from the storm center) with a maximum wind of about $55 \mathrm{~m} \mathrm{~s}^{-1}$ on the east flank.

The track of the control experiment (Fig. 2a) shows that the storm moves northward in the first $6 \mathrm{~h}$, goes north-northwestward until $24 \mathrm{~h}$, then stays nearly stationary and loops for $12 \mathrm{~h}$ before it finally turns eastward. The minimum SLP of the control experiment (Table 2; Fig. 2b) remains between 972 and $962 \mathrm{hPa}$ during the $60-\mathrm{h}$ integration, with the maximum wind (Table 3; Fig. 2c) ranging between 34 and $48 \mathrm{~m} \mathrm{~s}^{-1}$. The track of the degraded experiment (Fig. 2a) is very different from the control experiment. The track error in the degraded experiment (verified against the track from the control experiment) is 93,201 , and $23 \mathrm{~km}$, for 12,24 , and $48 \mathrm{~h}$, respectively (see Table 4 for the list of track errors in all experiments). The reduction of the track error after $48 \mathrm{~h}$ is likely sheer luck as the simulated track in the degraded experiment coincidentally matches the track in the control experiment after its sharp eastward deflection. The initial minimum SLP of the degraded experiment is $995 \mathrm{hPa}$ (Table 2; Fig. 2b), with maximum wind at $13 \mathrm{~m} \mathrm{~s}^{-1}$ (Table 3; Fig. 2c), which is hardly comparable to the storm intensity in the control experiment.

\section{Sensitivity experiments}

A series of OSSEs (see Table 1 for the summary of all experiments) have been conducted to assess the potential impact of different variables on BDA. By taking different data for 4DVAR [e.g., the three-dimensional horizontal wind $(u, v)$, and/or surface pressure perturbation $\left(p_{s}^{\prime}\right)$ fields at every grid point of the entire innernest domain from the initial condition of the control experiment], each experiment produces its own initial conditions for the ensuing 60-h simulation to examine the track and intensity of the simulated cyclone. Note that we assume that new observations are all available on every model grid, which may have oversimplified the real situation. Nevertheless, it provides some insights into the impact of the most ideally available observations on data assimilation.

For the 4DVAR data assimilation, the initial condi- 

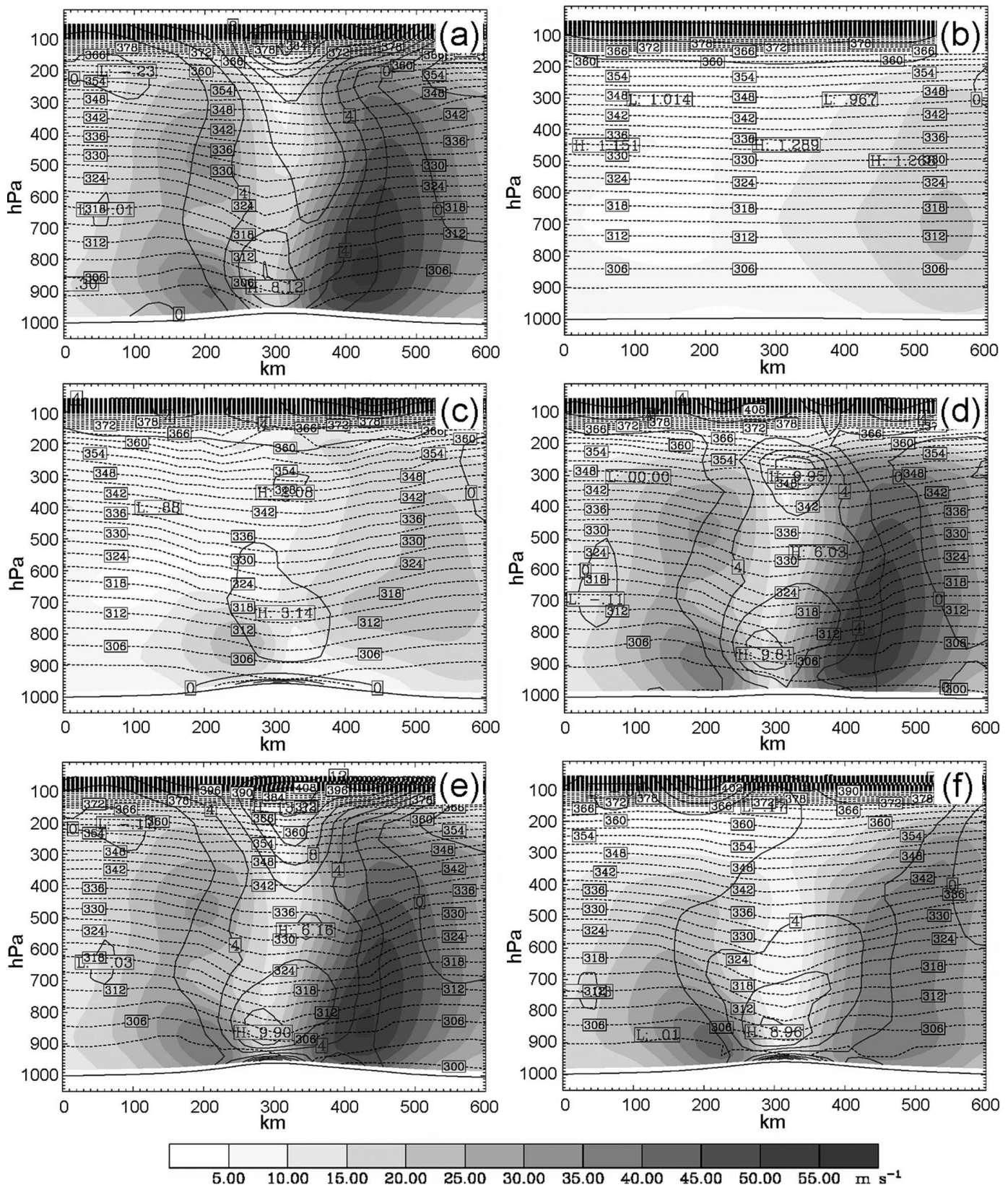

FIG. 3. West-east cross section through the storm center of potential vorticity (PVU; solid line), wind speed $\left(\mathrm{m} \mathrm{s}^{-1}\right.$; shaded according to the scale at the bottom), and potential temperature (K; dotted line) of the initial vortex structure for each experiment (Table 1): (a) control; (b) degraded, (c) A1, (d) A2, (e) A3, and (f) B1.

tion $\mathbf{x}\left(t_{0}\right)$ is obtained by minimizing the following cost function:

$$
\begin{aligned}
J= & \frac{1}{2}\left[\mathbf{x}\left(t_{0}\right)-\mathbf{x}_{b}\right]^{\mathrm{T}} \mathbf{B}^{-1}\left[\mathbf{x}\left(t_{0}\right)-\mathbf{x}_{b}\right] \\
& +\sum_{t_{r}=0, t_{R}} \frac{1}{2}\left\{\mathbf{h}\left[\mathbf{x}\left(t_{r}\right)\right]-\mathbf{y}_{o}\right\}^{\mathrm{T}} \mathbf{O}^{-1}\left\{\mathbf{h}\left[\mathbf{x}\left(t_{r}\right)\right]-\mathbf{y}_{o}\right\},
\end{aligned}
$$

where $\mathbf{x}_{b}$ represents the background field taken from the initial condition of the degraded experiment, $\mathbf{y}_{o}$ is the observation field from the initial condition of the control experiment, the $\mathbf{B}$ and $\mathbf{O}$ are the background error covariance matrix and the observation error covariance matrix, respectively, $\mathbf{h}$ is the observation operator, and $t_{R}$ is the time window for data assimilation.

In our calculation, $\mathbf{B}$ is estimated according to the so-called National Centers for Environmental Prediction (NCEP) method (Parrish and Derber 1992) by taking the difference of the background field (i.e., the ini- 
TABLE 2. Intensity evolution (minimum SLP; $\mathrm{hPa}$ ) of the relevant experiments.

\begin{tabular}{|c|c|c|c|c|c|c|c|c|c|c|c|}
\hline Experiment & $0 \mathrm{~h}$ & $6 \mathrm{~h}$ & $12 \mathrm{~h}$ & $18 \mathrm{~h}$ & $24 \mathrm{~h}$ & $30 \mathrm{~h}$ & $36 \mathrm{~h}$ & $42 \mathrm{~h}$ & $48 \mathrm{~h}$ & $54 \mathrm{~h}$ & $60 \mathrm{~h}$ \\
\hline Control & 968 & 964 & 962 & 967 & 969 & 966 & 964 & 968 & 971 & 972 & 972 \\
\hline Degraded & 995 & 1000 & 998 & 997 & 996 & 994 & 995 & 992 & 991 & 991 & 992 \\
\hline $\mathrm{A} 1$ & 969 & 988 & 985 & 983 & 980 & 974 & 970 & 970 & 968 & 967 & 969 \\
\hline A2 & 989 & 972 & 970 & 968 & 969 & 965 & 965 & 967 & 964 & 965 & 968 \\
\hline A3 & 970 & 972 & 969 & 968 & 969 & 965 & 964 & 964 & 966 & 968 & 969 \\
\hline B1 & 971 & 974 & 971 & 964 & 965 & 967 & 968 & 969 & 963 & 964 & 968 \\
\hline B2 & 971 & 977 & 976 & 972 & 968 & 966 & 967 & 968 & 968 & 969 & 971 \\
\hline B3 & 975 & 980 & 977 & 975 & 975 & 971 & 970 & 969 & 972 & 972 & 971 \\
\hline O1 & 980 & 977 & 972 & 973 & 973 & 970 & 963 & 967 & 971 & 972 & 971 \\
\hline O5 & 972 & 974 & 970 & 968 & 971 & 967 & 966 & 965 & 966 & 967 & 967 \\
\hline O10 & 970 & 973 & 970 & 967 & 969 & 968 & 970 & 970 & 969 & 965 & 970 \\
\hline W & 965 & 970 & 965 & 966 & 968 & 967 & 962 & 964 & 969 & 970 & 969 \\
\hline
\end{tabular}

tial condition of the degraded experiment) between the initial and 12-h time. For simplicity, only the diagonal elements are used. The typical values of $\mathbf{B}^{-1}$ for $u, v$, and $p_{s}^{\prime}$ are 0.25 and $0.10 \mathrm{~m}^{-2} \mathrm{~s}^{2}$ and $0.83 \mathrm{hPa}^{-2}$, respectively [corresponding to wind errors of $2.0 \mathrm{~m} \mathrm{~s}^{-1}$ (for $u$ ) and $3.1 \mathrm{~m} \mathrm{~s}^{-1}$ (for $v$ ), and pressure error of $1.1 \mathrm{hPa}$. To emphasize the impact from the observations, we artificially assign the value of $\mathbf{O}^{-1}$ to be about 20 times the value of $\mathbf{B}^{-1}$ (W. Huang, 2003, personal communication). By doing so, the data assimilation blends the observations and background while forcing the analysis closer to the observations. Sensitivity to the uncertainty due to the use of $\mathbf{B}^{-1}$ will be discussed in section $3 \mathrm{c}$. In our experiments, the cost function is minimized within about 15 iterations of the backward adjoint integration, with the value of the cost function reduced by a factor of 80 for the experiment A3 [see Fig. 4 for the ratio of the cost function at each iteration $\left(J_{n}\right)$ to its initial value $\left(J_{0}\right)$; roughly at a value of 0.012$]$.

\section{a. Impacts from the assimilation of different variables}

\section{1) EXPERIMENT DESIGN}

This first set of experiments (see the third row in Table 1) is performed by assimilating different data from the initial condition of the control experiment into the initial condition of the degraded experiment through the 4DVAR with a 30-min assimilation window (same data assimilated every $6 \mathrm{~min}$, while assuming the TC vortex is fixed at the same location) to create the new initial conditions, and then running the model forward for $60 \mathrm{~h}$. The experiment A1 (A2; A3) represents a simulation starting with an initial condition after the $p_{s}^{\prime}\left(u, v ; u, v\right.$, and $\left.p_{s}^{\prime}\right)$ from which the control experiment is assimilated. The purpose of these experiments is to investigate the impact of different parameters on the storm initialization, as well as the subsequent forecast, through the 4DVAR.

\section{2) Results}

\section{(i) Initial structure}

If only the surface pressure field from the initial condition of the control experiment is assimilated (experiment A1), the maximum low-level wind (Fig. 3c) cannot be recovered. On the other hand, by assimilating only the 3D wind field from the initial condition of the control experiment (experiment A2), most of the vortex structure (Fig. 3d) is recovered. The comparison of experiments $\mathrm{A} 1$ and $\mathrm{A} 2$ indicates that to recover the

TABLE 3. The maximum azimuthally averaged tangential wind $\left(\mathrm{m} \mathrm{s}^{-1}\right)$ at the model level of $\sigma=0.87$ of the relevant experiments.

\begin{tabular}{|c|c|c|c|c|c|c|c|c|c|c|c|}
\hline Experiment & $0 \mathrm{~h}$ & $6 \mathrm{~h}$ & $12 \mathrm{~h}$ & $18 \mathrm{~h}$ & $24 \mathrm{~h}$ & $30 \mathrm{~h}$ & $36 \mathrm{~h}$ & $42 \mathrm{~h}$ & $48 \mathrm{~h}$ & $54 \mathrm{~h}$ & $60 \mathrm{~h}$ \\
\hline Control & 46 & 45 & 48 & 44 & 40 & 40 & 42 & 40 & 36 & 34 & 37 \\
\hline Degraded & 13 & 13 & 15 & 14 & 17 & 18 & 17 & 22 & 22 & 23 & 21 \\
\hline A1 & 16 & 24 & 28 & 29 & 32 & 35 & 37 & 36 & 39 & 39 & 37 \\
\hline $\mathrm{A} 2$ & 45 & 41 & 42 & 43 & 42 & 46 & 44 & 40 & 41 & 42 & 40 \\
\hline A3 & 45 & 41 & 43 & 43 & 42 & 44 & 44 & 42 & 42 & 39 & 38 \\
\hline B1 & 40 & 39 & 43 & 46 & 43 & 42 & 40 & 40 & 43 & 42 & 38 \\
\hline B2 & 39 & 37 & 38 & 41 & 44 & 44 & 42 & 40 & 39 & 39 & 37 \\
\hline B3 & 34 & 33 & 38 & 39 & 38 & 38 & 38 & 40 & 38 & 35 & 37 \\
\hline O1 & 39 & 36 & 41 & 40 & 38 & 39 & 44 & 41 & 36 & 35 & 36 \\
\hline $\mathrm{O} 5$ & 44 & 39 & 43 & 42 & 39 & 42 & 43 & 42 & 40 & 42 & 41 \\
\hline O10 & 45 & 40 & 43 & 43 & 39 & 43 & 40 & 38 & 39 & 41 & 35 \\
\hline $\mathrm{W}$ & 43 & 40 & 44 & 45 & 40 & 42 & 44 & 45 & 37 & 36 & 39 \\
\hline
\end{tabular}


TABLE 4. Track errors $(\mathrm{km})$ of the relevant experiments as compared to the control experiment.

\begin{tabular}{|c|c|c|c|c|c|c|c|c|c|c|c|}
\hline Experiment & $0 \mathrm{~h}$ & $6 \mathrm{~h}$ & $12 \mathrm{~h}$ & $18 \mathrm{~h}$ & $24 \mathrm{~h}$ & $30 \mathrm{~h}$ & $36 \mathrm{~h}$ & $42 \mathrm{~h}$ & $48 \mathrm{~h}$ & $54 \mathrm{~h}$ & $60 \mathrm{~h}$ \\
\hline Degraded & 33 & 166 & 93 & 202 & 201 & 194 & 188 & 119 & 23 & 60 & 33 \\
\hline $\mathrm{A} 1$ & 0 & 90 & 108 & 152 & 152 & 152 & 149 & 128 & 141 & 98 & 59 \\
\hline A 2 & 33 & 25 & 35 & 52 & 75 & 60 & 32 & 54 & 87 & 79 & 59 \\
\hline A3 & 0 & 25 & 35 & 52 & 75 & 61 & 32 & 37 & 70 & 52 & 20 \\
\hline B1 & 0 & 79 & 84 & 83 & 32 & 15 & 46 & 30 & 56 & 78 & 86 \\
\hline $\mathrm{B} 2$ & 0 & 45 & 91 & 90 & 92 & 60 & 39 & 59 & 45 & 15 & 32 \\
\hline B3 & 0 & 15 & 49 & 45 & 56 & 83 & 52 & 46 & 61 & 45 & 54 \\
\hline $\mathrm{O} 1$ & 0 & 22 & 33 & 78 & 74 & 91 & 60 & 49 & 74 & 79 & 24 \\
\hline $\mathrm{O} 5$ & 0 & 22 & 33 & 60 & 74 & 74 & 60 & 37 & 60 & 94 & 72 \\
\hline O10 & 0 & 25 & 33 & 60 & 83 & 86 & 60 & 51 & 98 & 46 & 35 \\
\hline $\mathrm{W}$ & 0 & 49 & 63 & 100 & 70 & 79 & 63 & 70 & 97 & 92 & 89 \\
\hline
\end{tabular}

initial storm structure, the wind field is a crucial parameter to be assimilated. ${ }^{1}$ This result is in good agreement with $\mathrm{Pu}$ and Braun (2001).

When both the $3 \mathrm{D}$ wind and surface pressure data from the initial condition of the control experiment (experiment A3) are assimilated to the degraded initial condition through 4DVAR, an asymmetric vortex structure (Fig. 3e), consistent with (although not identical to) that of the control experiment (Fig. 3a), is produced. The slight difference from the structure of the control experiment results from the fact that the assimilation process tries to minimize the cost function that contains both the background (i.e., from the degraded experiment) and observation terms (i.e., from the control experiment). As the background information is also taken into consideration (although with a much weaker weighting), the assimilated results cannot be identical to the control experiment.

\section{(ii) Intensity evolution}

When only the surface pressure field is assimilated in experiment A1, the minimum central SLP of the storm (969 hPa; Fig. 5a) is well recovered during the initial time. However, the initial wind field is severely underestimated (by about $30 \mathrm{~m} \mathrm{~s}^{-1}$; Fig. 5b). Because of such a large dynamic imbalance between the wind and mass fields, geostrophic adjustment occurs quickly in the first few hours of the integration in experiment $\mathrm{A} 1$, and the

\footnotetext{
${ }^{1}$ Note that one may ask why we do not assimilate the 3D pressure field in the BDA so as to have a fair comparison with the result of $\mathrm{A} 2$ that assimilates the $3 \mathrm{D}$ wind field. When the $3 \mathrm{D}$ pressure field is assimilated (experiments not shown), the initial vortex structure in the lower troposphere remains similar to A1, despite the more complicated feature in the upper troposphere. To be consistent with the works of Xiao et al. (2000) and Pu and Braun (2001), where SLP is used in their BDA, this paper simply discusses the BDA of the surface pressure field, not the 3D pressure field.
}

minimum central SLP fills immediately after the integration starts. Thus, large intensity errors are induced.

In experiment $\mathrm{A} 2$, the maximum azimuthally averaged tangential wind at $\sigma=0.87$ is identical to the control experiment of $45 \mathrm{~m} \mathrm{~s}^{-1}$ at the initial time, while the minimum central SLP is higher than that of the control experiment by $21 \mathrm{hPa}$ (see Fig. 5a). The evolution of the maximum azimuthally averaged tangential wind of experiment A2 (Fig. 5b) agrees well (within 5\% error) with the control experiment throughout the integration period, while the minimum central SLP adjusts quickly toward the value of the control experiment (although still a few hectopascals higher) and remains close to the control experiment for the rest of the simulation.

In experiment A3 (see Figs. 5a,b), both the initial maximum azimuthally averaged tangential wind and

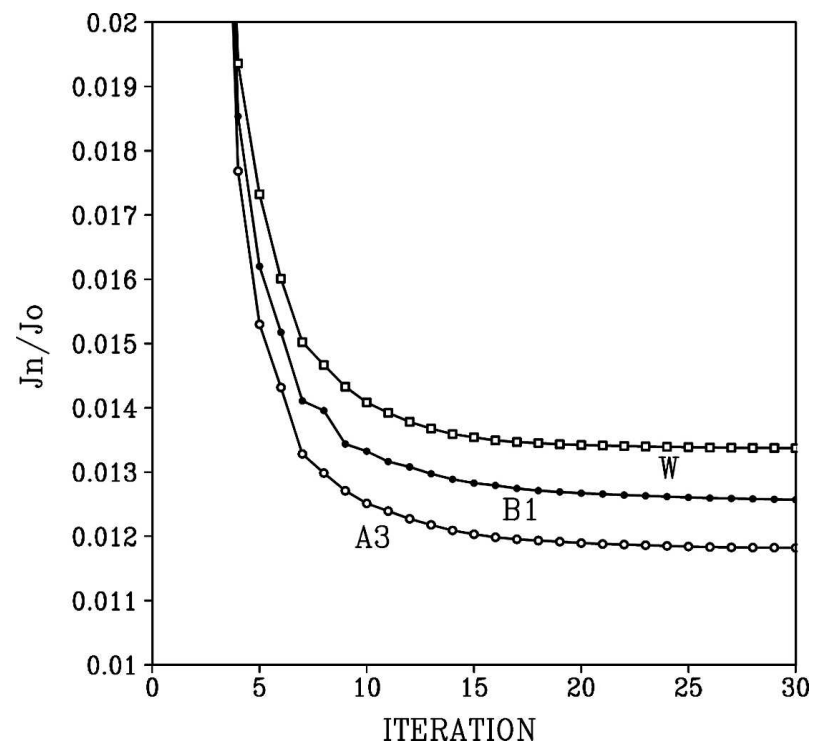

FIG. 4. Ratio of the cost function at each iteration $\left(J_{n}\right)$ to its initial value $\left(J_{0}\right)$ in experiments A3, B1, and W. 


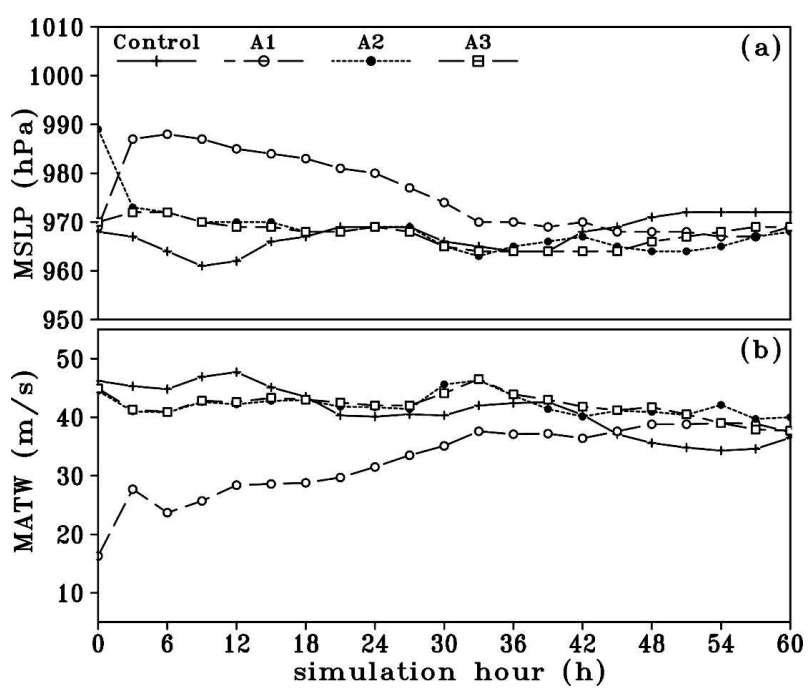

FIG. 5. Time evolutions of (a) the minimum central sea level pressure (MSLP; hPa) and (b) the maximum azimuthally averaged tangential wind $\left(\mathrm{m} \mathrm{s}^{-1}\right)$ at the model level of $\sigma=0.87$ in the control experiment, $\mathrm{A} 1, \mathrm{~A} 2$, and $\mathrm{A} 3$.

the minimum central SLP match those of the control experiment perfectly, and their evolution at later stages is consistent with experiment A2.

\section{(iii) Geostrophic adjustment}

By comparing the results from experiments A1, A2, and $\mathrm{A} 3$, it is obvious that assimilation of the $3 \mathrm{D}$ wind field plays a more important role than that of the surface pressure field for the TC initialization and prediction. More specifically, the wind information has a longer memory after the assimilation than the surface pressure information does, which is consistent with the result of Pu and Braun (2001), but not with that of Xiao et al. (2000). More insight into the relative importance of assimilating wind and pressure fields discovered so far can be generated based on the geostrophic adjustment argument (Schubert et al. 1980). For example, if the radius of maximum wind $(L)$ is small compared to the radius of deformation $\left(L_{R}\right)$, that is, $L / L_{R} \ll 1$, the initial tangential wind and vorticity fields would have little change (pressure adjusts to wind).

Using the definition of the local $L_{R}\left[L_{R}=N H /(\bar{\eta} \bar{\xi})^{1 / 2}\right.$, where $N$ is the buoyancy (Brunt-Väisälä) frequency and $H$ is the vertical scale of the motion] from Shapiro and Montgomery (1993), we can estimate the value of $L / L_{R}$ in each experiment (see Table 5). The low value of $L / L_{R}$ in both A1 and A2 (Table 5) favors a geostrophic adjustment of the pressure field toward the wind field. This explains why the pressure field quickly adjusts to the wind field, and thus the storm intensity in terms of SLP is underestimated in A1 but is recovered in A2 during the assimulation and the subsequent simu-
TABLE 5. Estimation of the ratio of $L$ to $L_{R}$. XZW denotes Hurricane Fran in Xiao et al. (2000), PB-Georges represents Hurricane Georges in $\mathrm{Pu}$ and Braun (2001). (Here $N$ is the static stability, $H$ is the vertical scale, $V_{\max }$ is the maximum surface wind speed, and $L$ is estimated by the radius of $V_{\text {max }}$.)

\begin{tabular}{lcccc}
\hline & $\mathrm{A} 1$ & $\mathrm{~A} 2$ & $\mathrm{~PB}-G e o r g e s$ & $\mathrm{XZW}$ \\
\hline Latitude & $22^{\circ} \mathrm{N}$ & $22^{\circ} \mathrm{N}$ & $18^{\circ} \mathrm{N}$ & $23^{\circ} \mathrm{N}$ \\
$N$ & $0.015 \mathrm{~s}^{-1}$ & $0.015 \mathrm{~s}^{-1}$ & $0.015 \mathrm{~s}^{-1}$ & $0.015 \mathrm{~s}^{-1}$ \\
$H$ & $10 \mathrm{~km}$ & $10 \mathrm{~km}$ & $10 \mathrm{~km}$ & $10 \mathrm{~km}^{-1}$ \\
$V_{\max }$ & $13 \mathrm{~m} \mathrm{~s}^{-1}$ & $45 \mathrm{~m} \mathrm{~s}^{-1}$ & $20 \mathrm{~m} \mathrm{~s}^{-1}$ & $12 \mathrm{~m} \mathrm{~s}^{-1}$ \\
$L$ & $330 \mathrm{~km}$ & $150 \mathrm{~km}$ & $230 \mathrm{~km}$ & $280 \mathrm{~km}$ \\
$L_{R}$ & $1120 \mathrm{~km}$ & $230 \mathrm{~km}$ & $680 \mathrm{~km}$ & $1050 \mathrm{~km}$ \\
$L / L_{R}$ & 0.29 & 0.65 & 0.34 & 0.27 \\
\hline
\end{tabular}

lation. Examining the results from $\mathrm{Pu}$ and Braun (2001) and Xiao et al. (2000), we found that the $L / L_{R}$ values in their studies were also much less than one (Table 5), and thus the pressure field should adjust to the wind field. This was the case for Pu and Braun (2001), but not for Xiao et al. (2000). The result from the latter thus might be problematic and needs exploring in more detail.

In summary, the geostrophic adjustment argument explains that with the small value of $L / L_{R}$ of all the analyses above, the wind field should play a more important role than pressure for the initialization of TCs using the BDA technique.

\section{b. Impact from a bogused initial vortex and the vortex movement}

\section{1) EXPERIMENT DESIGN}

For practical model prediction of TCs, the initial vortex information is usually not adequate because of the lack of in situ observations and the uncertainty of the intensity estimation based on satellite data. In other words, experiment A3 may have assimilated the ideal vortex information from the control experiment that was not available in the real world. To tackle this problem, in many models, a bogused vortex spun up from a separate simulation/prediction is generally adopted (Kurihara et al. 1995; Wu et al. 2002). Therefore, to address the impact of the uncertainty in the initial vortex, experiment B1 is conducted, in which the assimilation is similar to A3 except that the vortex information in the core region is replaced by that from the $12-\mathrm{h}$ model integration (1200 UTC 28 September) of the control experiment. In other words, the vortex information inside the core region is obtained from the inner $300-\mathrm{km}$-radius vortex structure at 1200 UTC 28 September of the control experiment, with a linear transition zone between the $300-$ and $600-\mathrm{km}$ radius to smoothly blend the inner $300-\mathrm{km}$ vortex at 1200 UTC 
28 September with the wind and surface pressure data outside the core region of the control experiment at 0000 UTC 28 September. In this regard, experiment B1 (see the fourth row in Table 1) is designed to show the potential impact from such a "quasi bogused" vortex.

For another, in all of the previous experiments, the TC vortex is fixed in the geographic location during the assimilation period. To clearly demonstrate the steering effect during this assimilation period, a new approach is designed to allow the model vortex to move in time according to the track of the control experiment within a longer assimilation time window ( 3 or $6 \mathrm{~h}$ ) in BDA. It is hypothesized that better initial storm movement can be captured in the initial 3 (6) h through this new BDA procedure. This approach is consistent with the concept of vortex repositioning used in Jones and DeMaria (1999), where they used the barotropic model and its adjoint equations for data assimilation. Experiment B2 (B3) is the same as experiment B1, except that the TC vortex is allowed to move according to its actual position in the control experiment during the 3-h (6-h) assimilation time window.

\section{2) Result}

For experiment B1, the 12-h (1200 UTC 28 September) vortex structure from the initial condition of the control experiment is assimilated. As compared to Fig. $3 \mathrm{a}$, some of the asymmetric structure is captured in Fig. $3 \mathrm{f}$, yet the wind speed on the east (west) flank appears weaker (stronger). The difference between the control experiment and experiment B1 roughly indicates the uncertainty when a presimulated vortex is implanted to create the initial vortex condition in a TC simulation, as used in most real-case TC simulations (Kurihara et al. 1998; Liu et al. 1997; Wu et al. 2002) where a reasonable model simulation of the TC track and structure can be obtained.

Although based on a different initial vortex for data assimilation, note that the cost function in experiment B1 is still minimized quite efficiently, with the value of the cost function reduced by a factor of 75 in about 15 iterations (i.e., the value of $J_{n} / J_{0}$ of 0.013 in Fig. 4). As already seen from Fig. 3f, the initial vortex's asymmetric structure is generally recovered, although with slightly weaker intensity (see Tables 2 and 3 ) as compared to the control experiment as well as experiment A3.

The track of experiment B1 (figures not shown; see Table 4) was slightly degraded in the first $18 \mathrm{~h}$, while it improved slightly during 24-30 h, and then remained comparable to the error of the experiment A3. Over all, the use of a different vortex in the core region in B1 does not have much impact on the track as compared to A3. Meanwhile, the whole intensity evolution (figures

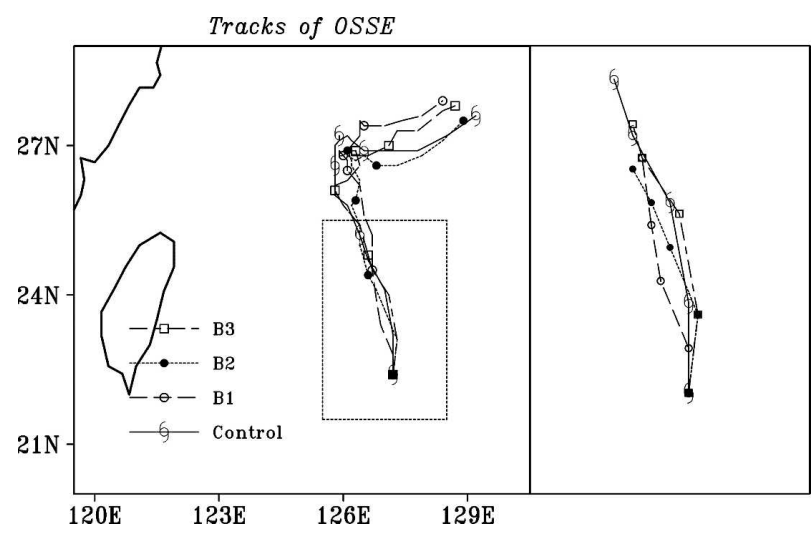

FIG. 6. Simulated tracks in the control experiment and experiments B1, B2, and B3: the storm positions for every (left) $12 \mathrm{~h}$ and (right) $3 \mathrm{~h}$ (but only for the first 12 -h track).

not shown) is similar to that in experiment A3 (Tables 2 and 3), although generally weaker than the control experiment after $42 \mathrm{~h}$.

In the previous experiments, as well as the available publications on BDA (e.g., Zou and Xiao 2000; Xiao et al. 2000; Pu and Braun 2001), the vortex is fixed in position during the data assimilation period. To elaborate the procedures for $\mathrm{BDA}$, two separate experiments (experiments B2 and B3) are conducted by allowing the model vortex to move according to the track of the control experiment within a longer assimilation time window ( 3 and $6 \mathrm{~h}$, respectively). The track errors (Table 4$)$ are $45(15,15), 79(45,15), 91(70,25)$, and 84 $(91,49)$ in experiment B1 (B2, B3) at 3, 6, 9, and $12 \mathrm{~h}$, respectively. These results (also see Fig. 6, right) thus clearly indicate that the simulated storm position at the first $9 \mathrm{~h}$ is much improved compared to the case (B1) without considering the vortex movement during the data assimilation window, and that the improvement is more significant with a longer assimilation time window. In other words, the 3- or 6-h cycle data assimilation allowing the vortex to move following the actual track is successful in correcting the initial steering flow to some degree. This success may partly result from the inclusion of the assimilated tendency due to the vortex movement during the BDA period. This can shed some light on improving the TC initialization based on the BDA.

It should be noted that the improvement in the track prediction of experiments B2 and B3 over experiment B1 after $12 \mathrm{~h}$ is not significant because of the subsequent eastward turn of the model storm. This again indicates that information from both the vortex and large-scale environment has to be well injected simultaneously into the BDA in order to obtain realistic simulations/predictions of TC tracks. 


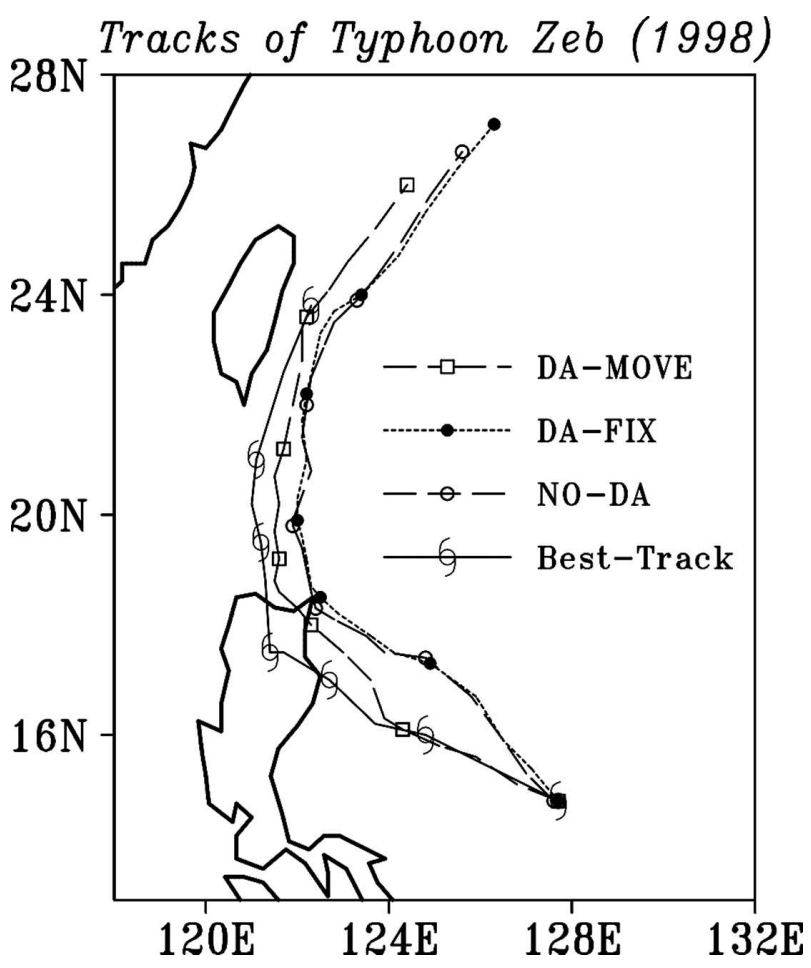

FIG. 7. The 72-h JTWC best track (indicated with typhoon symbol) and the simulated storm tracks from experiments NODA, DA-FIX, and DA-MOVE for Typhoon Zeb (1998), shown for 12 -h intervals from 0000 UTC 13 Oct to 0000 UTC 16 Oct 1998.

As an example of the application of the method suggested above, we simulate the track of Typhoon Zeb (1998) (see Wu et al. 2003) with three numerical experiments (with $30-\mathrm{km}$ resolution). One is a standard MM5 simulation with an initial bogused vortex following $\mathrm{Wu}$ et al. (2002) without data assimilation (denoted as NO-DA), another experiment assimilated the above bogused vortex (fixed in location) based on a 30-min window 4DVAR data assimilation (similar to B1; denoted as DA-FIX), and the other is a simulation in which the vortex was assimilated with the same initial data except it moved in a 3-h window assimilation (similar to B2; denoted as DA-MOVE).

Very little difference is found between the tracks of NO-DA and DA-FIX (Fig. 7). However, the track is improved dramatically (especially in the first $12 \mathrm{~h}$ ) in DA-MOVE. The model storm in DA-MOVE consistently follows the best track and moves toward the island of Luzon, while the model storms in both NO-DA and DA-FIX drift away to the north. The track error at $12 \mathrm{~h}$ in DA-MOVE is $55 \mathrm{~km}$, which is much smaller than the errors of 156 and $145 \mathrm{~km}$ in NO-DA and DAFIX, respectively. Therefore, it is clear that implantation of a movable presimulated/observed vortex into the 4DVAR can potentially improve the track forecasts, especially during the early hours.

\section{c. Discussions}

\section{1) BACKGROUND AND OBSERVATION ERROR COVARIANCE}

As mentioned earlier, the choice of $\mathbf{B}^{-1}$ and $\mathbf{O}^{-1}$ is another issue for data assimilation. In our experiments, we have simply assigned the value of $\mathbf{O}^{-1}$ to be $20 \times$ $\mathbf{B}^{-1}$. We have tested the impact by varying the value of $\mathbf{O}^{-1}$. As an example, experiment $\mathrm{O} 5(\mathrm{O} 10)$ (see the sixth row in Table 1) is conducted by assigning the value of $\mathbf{O}^{-1}$ to be 5 (10) times the value of $\mathbf{B}^{-1}$. It is found that the results in both track and intensity are generally not sensitive to such changes (see Tables 2, 3, 4; figures not shown). When we represent $\mathbf{O}^{-1}$ by the same value as $\mathbf{B}^{-1}$ (i.e., the experiment $\mathrm{O} 1$ ), an initially weaker vortex is obtained (Tables 2,3) because the weighting on the observation term becomes much smaller in $\mathrm{O} 1$ than in A3. This would affect the first 12-h intensity simulation, but after that the result remains about the same in the track and the intensity. Nevertheless, the above representation of $\mathbf{B}^{-1}$ and $\mathbf{O}^{-1}$ is still rather crude. We believe that a more sophisticated choice of $\mathbf{B}^{-1}$ and $\mathbf{O}^{-1}$ still needs to be addressed (such as Barker et al. 2004) in the future work to make a better 4DVAR data assimilation.

\section{2) THE IDENTICAL TWIN PROBLEM}

We have also performed the quasi OSSEs by using the Weather Research and Forecasting Model (WRF; Michalakes et al. 2001) to generate the vortex structure to be assimilated into the data assimilation system of MM5 (denoted as experiment W; see the bottom row in Table 1). This is attempted to avoid the so-called "identical twin" issue in our OSSEs. We generally reach the same results as discussed above. It can also be seen in Fig. 4 that the cost function in experiment $\mathrm{W}$ is minimized as efficiently as in experiment $\mathrm{A} 3$, with the value of the cost function reduced by a factor of 70 (equivalent to the ratio of 0.014 in Fig. 4). Therefore, the quick reduction of the cost function is not simply a result of the identical twin experiments, and the conclusions from our OSSEs are not overoptimistic due to the setup of the identical twin experiments.

\section{Summary}

A number of numerical experiments have been performed to investigate the initialization and prediction of TCs. A control experiment is carried out to create 
the imaginary "nature" data for Typhoon Zane (1996) using MM5. Then the initial data from the control experiment are degraded to produce the new initial condition and simulation of the degraded experiment, which mimics how a typical global analysis can resolve the Zane circulation. By assimilating some variables from the initial data of the control experiment into the degraded initial condition based on 4DVAR, one can gain insight into the key parameters for improving the initial condition and prediction of TCs. Two key issues have been addressed in the paper as follows.

\section{a. The relative importance of wind versus pressure}

The result shows that the wind field is critical for maintaining a correct initial vortex structure of a TC. On the other hand, the model's memory of the pressure field is relatively short. Therefore only when the surface pressure field is assimilated, due to the imbalance between the pressure and wind fields, does the pressure field adjust to the wind field and the pressures rise quickly. Consistent with Pu and Braun (2001), we show that the assimilation of the wind field is more successful in maintaining the vortex structure than that of only the SLP field. We also demonstrate that the above results can be interpreted based on the geostrophic adjustment theory. In other words, in all our experiments and previous experiments (Xiao et al. 2000; $\mathrm{Pu}$ and Braun 2001) using BDA, the scale of a TC vortex is generally much smaller than the radius of Rossby deformation. Therefore, the geostrophic adjustment favors the pressure field to adjust to the wind field and thus a better initial condition in the wind field is critical to the BDA and simulation/prediction of TCs.

\section{b. A new BDA method-Allowing the vortex to move during the data assimilation}

Considering the movement of the TC vortex during the data assimilation window can improve the track prediction, particularly in the early integration period. Such an improvement results from the fact that the vortex movement tendency is taken into account during the BDA period and thus partially corrects the steering effect in the early prediction/simulation period. This concept provides a new and possible approach to the improvement of TC track prediction. It is worthwhile to test this method in more real-case studies for general application.

In all, this study evaluates the uncertainty of the initial structure of a TC and its impact on the storm simulation. We note, however, that the generality of the results needs to be further examined from more case studies. Therefore, we plan to stretch such quasi OSSEs and apply them to more real cases by assimilating different special observations [e.g., Special Sensor Microwave Imager Precipitable Water (SSM/I-PW; Chen et al. 2004), Global Position System (GPS) meteorology (Wu et al. 2000c), GPS dropsonde (Wu et al. 2005), and radar data (Lee et al. 1999), etc.] in a future study. Such work can provide valuable information on the impact of each data type. Meanwhile, sensitivity tests based on the adjoint system (Zou et al. 1997) should also be performed in the future to identify the most sensitive regions and variables (Kleist and Morgan 2005) that affect the TC evolution in numerical models. The results from these studies would provide guidance for developing targeted observation strategies for TCs, such as the aircraft surveillance using GPS dropsondes (Baker and Daley 2000; Bishop et al. 2001; Majumdar et al. 2002a, b; Aberson 2002, 2003; Wu et al. 2005).

Acknowledgments. We thank Yong-Run Guo and Wei Huang at the MMM Division of NCAR for their assistance in using the MM5 4DVAR system for this study. Helpful discussions with Xiaolei Zou, Zhaoxia $\mathrm{Pu}$, and Qingnong Xiao are also appreciated. Detailed helpful remarks from the anonymous reviewers are acknowledged. We also thank the National Center for High-Performance Computing for providing the valuable computation resources. The work is supported by NSC 91-2111-M-002-024 and NSC 91-2119-M-002-032. Yuqing Wang acknowledges the support of the U.S. Office of Naval Research under Grant N00014-0210532, the National Science Foundation under Grant ATM-0119490, and the Frontier Research System for Global Change through its support to the International Pacific Research Center at the University of Hawaii.

\section{REFERENCES}

Aberson, S. D., 2002: Two years of operational hurricane synoptic surveillance. Wea. Forecasting, 17, 1101-1110.

_ 2003: Targeted observations to improve operational tropical cyclone track forecast guidance. Mon. Wea. Rev., 131, 16131628.

Baker, N. L., and R. Daley, 2000: Observation and background adjoint sensitivity in the adaptive observation-targeting problem. Quart. J. Roy. Meteor. Soc., 126, 1431-1454.

Barker, D. M., W. Huang, Y.-R. Guo, A. J. Bourgeois, and Q. N. Xiao, 2004: A three-dimensional variational data assimilation system for MM5: Implementation and initial results. Mon. Wea. Rev., 132, 897-914.

Bishop, C. H., B. J. Etherton, and S. J. Majumdar, 2001: Adaptive sampling with the ensemble transform Kalman filter. Part I: Theoretical aspects. Mon. Wea. Rev., 129, 420-436.

Blackadar, A. K., 1979: High resolution models of the planetary boundary layer. Advances in Environmental Science and Engineering, Vol. 1, J. Pfafflin and E. Ziegler, Eds., Gordon and Breach, 50-85.

Braun, S. A., 2002: A cloud-resolving simulation of Hurricane 
Bob (1991): Storm structure and eyewall buoyancy. Mon. Wea. Rev., 130, 1573-1592.

Burpee, R. W., J. L. Franklin, S. Lord, R. E. Tuleya, and S. Aberson, 1996: The impact of Omega Dropwindsonde on operational hurricane track forecast models. Bull. Amer. Meteor. Soc., 77, 925-933.

Chen, S.-H., F. C. Vandenberghe, G. W. Petty, and J. F. Bresch, 2004: Application of SSM/I satellite data to a hurricane simulation. Quart. J. Roy. Meteor. Soc., 130, 801-825.

Dudhia, J., 1989: Numerical study of convection observed during the Winter Monsoon Experiment using a mesoscale twodimensional model. J. Atmos. Sci., 46, 3077-3107.

, 1993: A nonhydrostatic version of the Penn State/NCAR Mesoscale Model: Validation tests and simulation of an Atlantic cyclone and cold front. Mon. Wea. Rev., 121, 14931513.

Grell, G. A., 1993: Prognostic evaluation of assumptions used by cumulus parameterization. Mon. Wea. Rev., 121, 764-787.

Guo, Y.-R., Y.-H. Kuo, J. Dudhia, D. Parsons, and C. Rocken, 2000: Four-dimensional variational data assimilation of heterogeneous mesoscale observations for a strong convective case. Mon. Wea. Rev., 128, 619-643.

Jones, R. W., and M. DeMaria, 1999: Further studies of the optimization of a hurricane track prediction model using the adjoint equations. Mon. Wea. Rev., 127, 1586-1598.

Kleist, D. T., and M. C. Morgan, 2005: Interpretation of the structure and evolution of adjoint-derived forecast sensitivity gradients. Mon. Wea. Rev., 133, 467-485.

Kummerow, C., and Coauthors, 2000: The status of the Tropical Rainfall Measuring Mission (TRMM) after two years in orbit. J. Appl. Meteor., 39, 1965-1982.

Kuo, Y.-H., X. Zou, and W. Huang, 1997: The impact of global positioning system data on the prediction of an extratropical cyclone: An observing system simulation experiment. Dyn. Atmos. Oceans, 27, 439-470.

Kurihara, Y., M. A. Bender, and R. J. Ross, 1993: An initialization scheme of hurricane models by vortex specification. Mon. Wea. Rev., 121, 2030-2045.

— - — , R. E. Tuleya, and R. J. Ross, 1995: Improvements in the GFDL hurricane prediction system. Mon. Wea. Rev., 123, 2791-2801.

,,--- , and,- 1998 : The GFDL hurricane prediction system and its performance in the 1995 hurricane season. Mon. Wea. Rev., 126, 1306-1322.

Lee, W. C., B. J.-D. Jou, P.-L. Chang, and S.-M. Deng, 1999: Tropical cyclone kinematic structure retrieved from singleDoppler radar observations. Part I: Interpretation of Doppler velocity patterns and the GBVTD technique. Mon. Wea. Rev., 127, 2419-2439.

Liu, W. T., 2002: Progress in scatterometer application. J. Oceanogr., 58, 121-136.

Liu, Y., D.-L. Zhang, and M. K. Yau, 1997: A multiscale numerical study of Hurricane Andrew (1992). Part I: Explicit simulation and verification. Mon. Wea. Rev., 125, 3073-3093.

,-- , and — 1999: A multiscale numerical study of Hurricane Andrew (1992). Part II: Kinematics and inner-core structures. Mon. Wea. Rev., 127, 2597-2616.

Majumdar, S. J., C. H. Bishop, R. Buizza, and R. Gelaro, 2002a: A comparison of ensemble-transform Kalman-filter targeting guidance with ECMWF and NRL total-energy singularvector guidance. Quart. J. Roy. Meteor. Soc., 128, 2527-2549.

$\longrightarrow$, - B. J. Etherton, and Z. Toth, 2002b: Adaptive sampling with the ensemble-transform Kalman filter. Part II: Field program implementation. Mon. Wea. Rev., 130, 1356-1369.

Michalakes, J., S. Chen, J. Dudhia, L. Hart, J. Klemp, J. Middlecoff, and W. Skamarock, 2001: Development of a nextgeneration regional weather research and forecast model. Developments in Teracomputing: Proceedings of the Ninth ECMWF Workshop on the Use of High Performance Computing in Meteorology, W. Zwiefnofer and N. Kreitz, Eds., World Scientific, 269-276.

Morss, R. E., K. A. Emanuel, and C. Snyder, 2001: Idealized adaptive observation strategy for improving numerical weather prediction. J. Atmos. Sci., 58, 210-232.

Negri, A. J., and R. F. Adler, 1993: An intercomparison of three satellite infrared rainfall techniques over Japan and surrounding waters. J. Appl. Meteor., 32, 357-373.

Parrish, D. F., and J. C. Derber, 1992: The National Meteorological Center's spectral statistical-interpolation analysis system. Mon. Wea. Rev., 120, 1747-1763.

Pu, Z.-X., and S. A. Braun, 2001: Evaluation of bogus vortex techniques with four-dimensional variational data assimilation. Mon. Wea. Rev., 129, 2023-2039.

—, W.-K. Tao, S. Braun, J. Simpson, Y. Jia, H. Halverson, W. Olson, and A. Hou, 2002: The impact of TRMM data on mesoscale numerical simulation of Supertyphoon Paka. Mon. Wea. Rev., 130, 2448-2458.

Schubert, W. H., J. J. Hack, P. L. Silva Dias, and S. R. Fulton, 1980: Geostrophic adjustment in an axisymmetric vortex. $J$. Atmos. Sci., 37, 1464-1484.

Shapiro, L. J., and M. T. Montgomery, 1993: A three-dimensional balance theory for rapidly rotating vortices. J. Atmos. Sci., 50, $3322-3335$.

Smith, E. A., and T. F. Lee, 1995: Seventh Conference on Satellite Meteorology and Oceanography. Bull. Amer. Meteor. Soc., 76, 363-371.

Soden, B. J., C. S. Velden, and R. E. Tuleya, 2001: The impact of satellite winds on experimental GFDL hurricane model forecasts. Mon. Wea. Rev., 129, 835-852.

Tuleya, R. E., and S. Lord, 1997: The impact of dropwindsonde data on GFDL hurricane model forecasts using global analyses. Wea. Forecasting, 12, 307-323.

Velden, C. S., C. M. Hayden, S. J. Nieman, W. P. Menzel, S. Wanzong, and J. S. Goerss, 1997: Upper-tropospheric winds derived from geostationary satellite water vapor observations. Bull. Amer. Meteor. Soc., 78, 173-195.

Wang, Y., 1998: On the bogusing of tropical cyclones in numerical models: The influence of vertical structure. Meteor. Atmos. Phys., 65, 153-170.

_ 2001: An explicit simulation of tropical cyclones with a triply nested movable mesh primitive equations model-TCM3. Part I: Model description and control experiment. Mon. Wea. Rev., 129, 1370-1394.

_ 2002a: An explicit simulation of tropical cyclones with a triply nested movable mesh primitive equations modelTCM3. Part II: Model refinements and sensitivity to cloud microphysics parameterization. Mon. Wea. Rev., 130, 30223036.

_, 2002 b: Vortex Rossby waves in a numerically simulated tropical cyclone. Part I: Overall structure, potential vorticity, and kinetic energy budgets. J. Atmos. Sci., 59, 1213-1238.

,2002c: Vortex Rossby waves in a numerically simulated tropical cyclone. Part II: The role in tropical cyclone structure and intensity changes. J. Atmos. Sci., 59, 1239-1262.

Wu, C.-C., M. Bender, and Y. Kurihara, 2000a: Typhoon forecasts 
with the GFDL hurricane model: Forecast skill and comparison of predictions using AVN and NOGAPS global analyses. J. Meteor. Soc. Japan, 78, 777-788.

- T.-S. Huang, K.-N. Huang, and T.-C. Yeh, 2000b: PV diagnostics of the impact of model initialization on the performance of a typhoon prediction system. Preprints, 24th Conf. on Hurricanes and Tropical Meteorology, Fort Lauderdale, FL, Amer. Meteor. Soc., 423-424.

- H.-C. Kuo, H.-H. Hsu, and B. J.-D. Jou, 2000c: Weather and climate research in Taiwan: Potential application of GPS/ MET data. Terr. Atmos. Oceanic Sci., 11, 211-234.

—, T.-H. Yen, Y.-H. Kuo, and W. Wang, 2002: Rainfall simulation associated with Typhoon Herb (1996) near Taiwan. Part I: The topographic effect. Wea. Forecasting, 17, 1001-1015.

— , K.-H. Chou, H.-J. Cheng, and Y. Wang, 2003: Eyewall contraction, breakdown and reformation in a landfalling typhoon. Geophys. Res. Lett., 30, 1887, doi:10.1029/2003GL017653.

— - and Coauthors, 2005: Dropsonde observations for typhoon surveillance near the Taiwan region (DOTSTAR): An overview. Bull. Amer. Meteor. Soc., 86, 787-790.

Xiao, Q., X. Zou, and B. Wang, 2000: Initialization and simulation of a landfalling hurricane using a variational bogus data assimilation scheme. Mon. Wea. Rev., 128, 2252-2269.
Zhang, D.-L., Y. Liu, and M. K. Yau, 2000: A multiscale numerical study of Hurricane Andrew (1992). Part III: Dynamically induced vertical motion. Mon. Wea. Rev., 128, 3772-3788.

,-- , and 2001: A multiscale numerical study of Hurricane Andrew (1992). Part IV: Unbalanced flows. Mon. Wea. Rev., 129, 92-107.

,-- , and - , 2002: A multiscale numerical study of Hurricane Andrew (1992). Part V: Inner-core thermodynamics. Mon. Wea. Rev., 130, 2745-2763.

Zhu, T., D.-L. Zhang, and F. Weng, 2002: Impact of the advanced microwave sounding unit measurements on hurricane prediction. Mon. Wea. Rev., 130, 2416-2432.

Zou, X., and Q. Xiao, 2000: Studies on the initialization and simulation of a mature hurricane using a variational bogus data assimilation scheme. J. Atmos. Sci., 57, 836-860.

— - W. Huang, and Q. Xiao, 1997: A user's guide to the MM5 adjoint modeling system. NCAR Tech. Note TN-437+IA, MMM division, $92 \mathrm{pp}$.

—, Q. Xiao, A. E. Lipton, and G. D. Modica, 2001: A numerical study of the effect of GOES sounder cloud-cleared brightness temperatures on the prediction of Hurricane Felix. J. Appl. Meteor., 40, 34-55. 